\title{
Secondary Osteosarcoma of Pelvic Bone: Long-Term Complication of Bladder Cancer Radiotherapy
}

\begin{abstract}
Second cancer in the irradiated area is one of the complication of radiotherapy of which bone and soft tissue sarcomas predominate. Radiation-induced osteosarcoma (RIOS)accounts for $3.4 \%-5.5 \%$ of all osteosarcoma cases. A 70-year old male presented with complaints of swelling and pain in left gluteal region without any antecedent trauma. On clinical examination $8 \times 8 \mathrm{~cm}$ size swelling palpable in left gluteal region arising form left iliac bone. He had history of bladder carcinoma 20 years ago for which he received concurrent chemoradiation. CT scan showed a large, erosive and lytic lesion of left iliac bone and biopsy of the lesion was suggestive of osteosarcoma. In view of extensive lesion eroding left half of pelvic bone, surgery was not done, and chemotherapy was planned.

Keywords: Pelvic bone, Radiotherapy, secondary osteosarcoma
\end{abstract}

\section{Introduction}

A long-term toxicity of radiotherapy (RT) is a second cancer in the irradiated fields. Among these, bone or soft tissue sarcoma account for the majority. Commonly reported sarcomas after RT are undifferentiated pleomorphic sarcoma, angiosarcoma, fibrosarcoma and malignant peripheral nerve sheath tumor. Radiation-induced osteosarcoma (RIOS) accounts for $3.4 \%-5.5 \%$ of all osteosarcoma cases. $^{[1]}$ These can be "skeletal" or, rarely, "extra-skeletal." Diseases attributed to RIOS are breast cancer, lymphoma, genitourinary cancer, retinoblastoma and head-and-neck cancer. The latency period exceeds 5 years in many cases. The latency period varies with the histological subtype. We report a case of osteosarcoma of pelvic bone in an elderly male treated with RT for bladder cancer 20 years ago.

\section{Case Report}

A 70-year-old-hypertensive, nondiabetic male without any comorbidities, presented with swelling and pain in the left gluteal region of 2 months duration. He denied any history of trauma. His vitals were stable and on examination, a firm-to-hard lump of $8 \mathrm{~cm} \times 8 \mathrm{~cm}$ size was palpable on the left gluteal region, arising from the left iliac bone. No impairment noted in distal neurovascular

This is an open access journal, and articles are distributed under the terms of the Creative Commons Attribution-NonCommercial-ShareAlike 4.0 License, which allows others to remix, tweak, and build upon the work non-commercially, as long as appropriate credit is given and the new creations are licensed under the identical terms.

For reprints contact: reprints@medknow.com functions in both legs. He received concurrent chemoradiation to the pelvis for urinary bladder carcinoma (urothelial carcinoma) 20 years ago. The exact stage and radiation schedule were not available. Computed tomography (CT) showed a large, erosive, and lytic lesion of the left iliac bone with subcutaneous satellite deposits [Figure 1]. A fine-needle aspiration of the mass was reported as showing dysplastic epithelial cells. At our center, a biopsy of the lesion showed hyperchromatic, spindle-to-polygonal-shaped cells with osteoid bone formation, suggestive of osteosarcoma [Figure 2]. Further staging work up with contrast-enhanced CT of the chest did not show lung metastasis and his recent cystoscopy was unremarkable. Surgery was not possible in view of the mass eroding half of the left pelvic bone with subcutaneous soft-tissue deposits. After explaining the prognosis and treatment options, he was started on chemotherapy with cisplatin and doxorubicin.

\section{Discussion}

A late complication of RT is cancer in the irradiated field. RIOS is serious complication. Among these, $50 \%-60 \%$ of radiation-induced sarcomas were OS..$^{[1]}$ OS can occur in the background of Paget's disease, bone infarction, exposure to radiation, and various clinical syndromes termed "secondary osteosarcoma." Patients with Li-Fraumeni syndrome are at

How to cite this article: Prasad KS, Bala S,
Ravichandran A, Sadashivudu G. Secondary
osteosarcoma of pelvic bone: Long-term complication
of bladder cancer radiotherapy. Indian J Med Paediatr
Oncol 2019;40:579-80.

\section{K Siva Prasad, Stalin Bala, Ambalathandi Ravichandran, Gundeti Sadashivudu}

Department of Medical Oncology, Nizam's Institute of Medical Sciences, Hyderabad, Telangana, India

Submission: 06-Apr-2018 Accepted in Revised Form: 21-Jun-2018

Published: 17-Feb-2020

Address for correspondence: Dr. Stalin Bala, Department of Medical Oncology, Nizam's Institute of Medical Sciences, Hyderabad, Telangana, India. E-mail: stalinchowdarybala@ gmail.com 


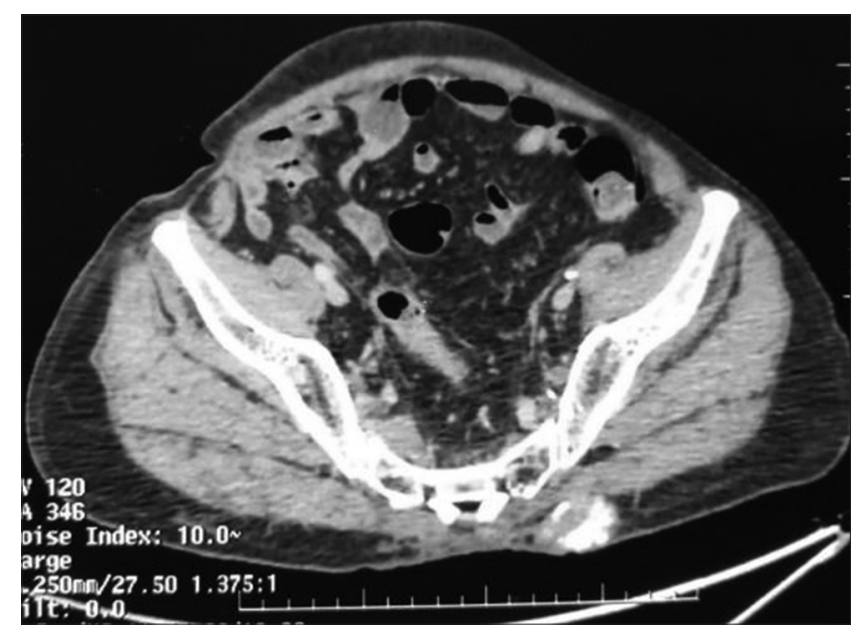

Figure 1: Computed tomography image showing subcutaneous osseous deposit

an increased risk of de novo and radiation-induced OS due to the increased DNA damage caused by ionizing radiation. It is estimated that the risk of developing RIOS in irradiated bone is $0.03 \%-0.8 \%{ }^{[1]}$ The latency period ranges from months to decades and typically occurs after 5-10 years. RT doses of $>30$ Gy carry high risk of radiation-induced sarcoma. These tumors typically arise at the edge of radiation fields, where partial injury to the adjacent tissue might cause-defective cell repair and may ultimately leads to malignant transformation. Damage to the TP53 and RB gene is believed to be the major factor in the pathogenesis of RIOS. DNA copy number and cytogenetics are complex in RIOS than in de novo OS. They commonly exhibit 3p loss, 1p loss (57\%), and TP53 (58\%). Histologically, OS is divided into several subtypes, based on morphology namely, osteoblastic, chondroblastic, fibroblastic, small cell, and telangiectatic variants. Secondary OS is a term used when a preexisting bone lesion transforms into malignancy. The two most common secondary OS are Paget's disease and radiation-induced. Commonest sites of RIOS are pelvis and shoulder region, but can occur in any irradiated site.

We could not find any published data on RIOS arising in the pelvic bone after bladder cancer therapy. In 1922, Beck reported a case of bone sarcoma after treatment of breast cancer with radiation. There are several case reports describing occurrence of RIOS in bladder, maxilla and mandible bone. Ferri et al. reported a case of OS arising in the bladder 27 years after RT for urothelial carcinoma. ${ }^{[2]}$ Mohan et al. reported a similar case of bladder osteosarcoma 8 months after RT. ${ }^{[3]}$ These two case reports had extraskeletal bladder osteosarcoma on histology.

The prognosis of radiation-induced sarcoma thought to be poor compared to de novo sarcoma, irrespective of site. Brady et al. reviewed 160 cases of radiation-induced sarcoma and on multivariate analysis metastatic disease, completeness of the surgery, and tumor size were the prognostic factors impacting the survival, and effect of site and histology type were insignificant. ${ }^{[4]}$

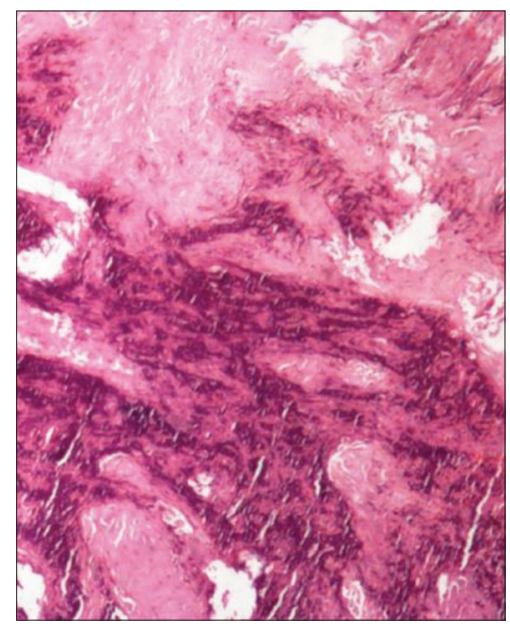

Figure 2: Histopathology showing osteoid formation with atypical cells

The incidence of radiation-induced sarcoma may rise in future because of increase in the survival of cancer patients. Poor prognosis is seen in pelvic, spinal, and shoulder girdle region RIOS. Better planning methods such as intensity-modulated RT and careful planning of dosimetry may prevent radiation-induced sarcoma in some cases. Long-term follow-up and a high index of suspicion are required in patients who were treated with RT.

\section{Declaration of patient consent}

The authors certify that they have obtained all appropriate patient consent forms. In the form the patient(s) has/have given his/her/their consent for his/her/their images and other clinical information to be reported in the journal. The patients understand that their names and initials will not be published and due efforts will be made to conceal their identity, but anonymity cannot be guaranteed.

\section{Acknowledgment}

The author would like to thank the Department of Radiology and Orthopedics, Nizam's Institute of Medical Sciences, Hyderabad.

Financial support and sponsorship

Nil.

\section{Conflicts of interest}

There are no conflicts of interest.

\section{References}

1. Ferrie BG, Imrie JE, Paterson PJ. Osteosarcoma of bladder 27 years after local radiotherapy. J R Soc Med 1984;77:962-3.

2. Mohan H, Ahal S, Nada R, Jogai S, Attri AK. Osteosarcoma of the bladder - A case report. Indian J Pathol Microbiol 2001;44:451-2.

3. Brady MS, Gaynor JJ, Brennan MF. Radiation-associated sarcoma of bone and soft tissue. Arch Surg 1992;127:1379-85.

4. Huvos AG, Woodard HQ, Cahan WG, Higinbotham NL, Stewart FW, Butler A, et al. Postradiation osteogenic sarcoma of bone and soft tissues. A clinicopathologic study of 66 patients. Cancer 1985;55:1244-55. 